\title{
Earthquake damage estimation of gas continuous buried pipelines
}

\author{
WANG Xiang-Jian 1,2,a , GUO En-Dong, ${ }^{1,2, b}$, YU Tian-Yang ${ }^{1,2, c}$ and LI Qian 1,2,d \\ ${ }^{1}$ Institute of Engineering Mechanics, China Earthquake Administration, Harbin 150080, China \\ ${ }^{2}$ Key Laboratory of Earthquake Engineering and Engineering Vibration of China Earthquake \\ Administration, Harbin 150080, China
}

awangxj@iem.ac.cn, biemged@263.net, ‘821677781@qq.com, d40253332@qq.com

Keywords: estimation; earthquake damage; earthquake damage index; weighted statistical average method; seismic wave propagation

\begin{abstract}
The semi-empirical and semi-theoretical method is adopted to simulate the response of gas continuous buried pipelines subjected to seismic wave propagation. Using the peak ground velocity (PGV) as the intensity measure, the maximum axial responses (strain or stress) of pipelines are calculated. The seismic safety factor is employed as earthquake damage index of a pipeline and the relation between earthquake damage index and earthquake damage level is presented to determine the earthquake damage level with respect to seismic intensity. The weighted statistical average method is introduced to estimate the earthquake damage indexes and earthquake damage states of pipeline network under different seismic intensities. According to the results of numerical example, it is concluded that the improved method is effective and practical.
\end{abstract}

\section{Introduction}

The earthquake damages of historical earthquake show that the lifeline systems, such as water, gas, transportation, electricity and communication, etc., are highly vulnerable, particularly the buried pipeline networks are often severely damaged when subjected to strong ground motion [1-6]. The gas leakage, caused by earthquake-induced damage to pipeline, may lead to serious secondary disasters, such as fire, explosion. They are the serious threats to the safety of resident's life and property, the social order of normal production and life, and the normal usage function of other lifeline systems and buildings and structures, and they greatly increase the difficulties of rehabilitation, post-earthquake relief and reconstruction. Therefore, it is of great necessary to evaluate the seismic performance or earthquake damage levels of gas pipeline network with respect to different seismic intensities.

The study on methods of earthquake damage estimation for buried pipeline network, which can be applied to pre-earthquake prediction and post-earthquake estimation of earthquake damage, are always among the research focuses of lifeline aseismic engineering [7-16]. Since the late 1960s when Newmark [10] and Sakurai and Takahashi [11] presented their simplified analytical methods for evaluating the response of a pipeline surrounded by an infinite elastic media, many estimation methods for the earthquake damage levels of buried pipelines, such as theoretical analysis methods, empirical statistics methods and hybrid methods combining theoretical analysis with empirical statistics based on earthquake damages [17], are proposed and extended by lots of researchers during the last five decades.

The purpose of this study is to investigate the damage levels for gas continuous buried pipelines with different seismic intensities subject to seismic wave propagation. The semi- empirical and semi-theoretical method is used for calculating the maximum axial strain or stress of a pipeline. And the seismic safety factor is employed as earthquake damage index of a pipeline. The weighted statistical average method is introduced to give the earthquake index and then determine the damage states of the pipeline network. 


\section{Semi-Empirical and Semi-Theoretical Method}

The stress of a buried pipeline due to seismic wave propagation is mainly induced by the relative displacement of the surrounding soil, and the effect of inertia force could be neglected. To the strain response of pipeline, the axial strain is bigger than others [13]. By ignoring the sliding at soil-pipe interface, the simplified analysis method to wave propagation assumes that the strain of pipeline is equal to the free field strain.

If the seismic wave is keeping the shear wave in the propagation process, the displacement of free field is

$$
u=f\left(x+c_{s} t\right) \sin \theta,
$$

where $u$ represents the displacement of free field in the axial direction of pipeline; $x$ is the distance of wave propagation in the propagation direction; $c_{s}$ is the shear wave velocity; $t$ is the time of wave propagation; $f(\cdot)$ is the displacement function; $\theta$ is the intersection angle between the axial direction of pipeline and the propagation direction of seismic wave.

The free field strain in the axial direction of pipeline is derived as

$$
\varepsilon(t)=\frac{V(t)}{2 c_{s}} \sin (2 \theta)
$$

where $\varepsilon(t)$ is the axial strain of pipeline; $V(t)$ is the velocity of free field. If $\theta=45^{\circ}$, the maximum strain of free field in the axial direction of pipeline is

$$
\varepsilon_{\max }=\frac{V_{\max }}{2 c_{s}},
$$

where $\varepsilon_{\max }$ is the maximum strain of free field in the axial direction of pipeline; $V_{\max }$ is the maximum velocity of free field, or peak ground velocity (PGV).

Actually, there is a certain slip at soil-pipe interface due to stiffness' remarkable difference between pipeline and soil. A conversion factor should be defined so as to account for the relation between the maximum strain of pipeline and soil in the axial direction of pipeline. The maximum axial strain of pipeline is expressed as

$$
\varepsilon_{p \max }=\xi_{\varepsilon_{\max }},
$$

where $\varepsilon_{p \max }$ is the maximum axial strain of pipeline; $\xi$ is the conversion factor obtained from empirical statistics method, and has the following expression,

$$
\begin{aligned}
& \xi=\frac{1}{1+\left(\frac{2 \pi}{L}\right)^{2} \frac{E A}{K_{1}}}, \\
& A=\pi(D+\tau) \tau, \\
& L=c_{s} T_{g}, \\
& K_{1}=\pi(D+2 \tau) k_{1},
\end{aligned}
$$

where $E$ is the elastic modulus of pipeline material, $\mathrm{MPa}=\mathrm{N} / \mathrm{mm}^{2} ; A$ is the cross-sectional area of pipeline, $\mathrm{mm}^{2} ; D$ is its inner diameter, $\mathrm{mm}$; $\tau$ is its wall thickness, $\mathrm{mm} ; L$ is the shear wave length, $\mathrm{mm}$; $c_{s}$ is the shear wave velocity at the depth of pipeline, $\mathrm{mm} / \mathrm{s} ; T_{g}$ is the characteristic period of the site of buried pipeline, $\mathrm{s} ; K_{1}$ is the soil resistance per unit length in axial direction, $\mathrm{N} / \mathrm{mm}^{2} ; k_{1}$ is the soil resistance per unit area in axial direction, and obtained from experiment or assigned to 0.06 without experimental data, $\mathrm{N} / \mathrm{mm}^{3}$.

For the safety requirement of gas supply system, the elastic constitutive relation is adopted for the continuous steel pipeline. So the maximum axial stress of pipeline is

$$
\sigma_{p \max }=E \varepsilon_{p \max },
$$

where $\sigma_{p \max }$ is the maximum axial stress of pipeline.

In this paper, the seismic safety factor is employed as earthquake damage index of a pipeline. So the earthquake damage index has the following expression, 


$$
D I=\delta \frac{R}{k S},
$$

where $D I$ is the earthquake damage index of a pipeline; $R$ is the allowable stress or strain of pipeline material, $k$ is its safety factor and $k=1.0-1.5 ; S$ is the maximum stress of strain of the pipeline, $\delta$ is the reduction factor for the current status of the service pipeline and $\delta=0.5-1.0$.

In order to evaluate the qualitative damage states of a relatively independent pipeline network, the weighted statistical average method is introduced to give a quantitative index, the earthquake index of the pipeline network with the following formula,

$$
D N=\frac{\sum_{i=1}^{n} L_{i} D I_{i}}{\sum_{i=1}^{n} L_{i}},
$$

where $D N$ is the earthquake damage index of pipeline network; $D I_{i}$ is the earthquake damage index of the $i$ th pipeline; $L_{i}$ is the length of the $i$ th pipeline; $n$ is the total number of pipelines. The relation between earthquake damage index and earthquake damage level is denoted in Table 1.

Table 1 Relation between earthquake damage index and earthquake damage level

\begin{tabular}{cccccc}
\hline EDI & $D N I \geq 1$ & $0.9 \leq D N I<1$ & $0.7 \leq D N I<0.9$ & $0.5 \leq D N I<0.7$ & $D N I<0.5$ \\
\hline EDL & Intact & Slight damage & Moderate damage & Severe damage & Destroy \\
\hline
\end{tabular}

Note: $D N I$ represents $D N$ or $D I$. EDI and EDL represents earthquake damage index and lelel.

\section{Numerical Example}

The relatively independent zone of gas pipeline network for this study is selected from a western city of China. All thirty-two main pipelines are continuous buried steel pipes, and their properties and engineering data were obtained, as summarized in Table 2. The yield stress of steel material is used as its ultimate stress. According to the seismic microzoning report, the site type is type II, the average value of measured shear velocity $c_{s}$ in $3 \mathrm{~m}$ depth of surface soil is about $200 \mathrm{~m} / \mathrm{s}$ and the characteristic period $T_{g}$ of the site of buried pipeline is $0.45 \mathrm{~s}$, as detailed in Table 3 . The safety factor $k$, the reduction factor for the current status of the service pipeline $\delta$ and the soil resistance per unit area in axial direction $k_{1}$ are shown in Table 3. For evaluating the earthquake damage level, PGV in respect of seismic intensity are denoted in Table 4.

Table 2 Properties and engineering data of gas pipeline

\begin{tabular}{cccccccc}
\hline No. & Material & $\begin{array}{c}\text { Material } \\
\text { type }\end{array}$ & $\begin{array}{c}\text { Elastic } \\
\text { modulus } \\
E[\mathrm{MPa}]\end{array}$ & $\begin{array}{c}\text { Yield } \\
\text { stress } \\
\sigma_{s}[\mathrm{MPa}]\end{array}$ & $\begin{array}{c}\text { Outer } \\
\text { diameter } \\
D[\mathrm{~mm}]\end{array}$ & $\begin{array}{c}\text { Wall } \\
\text { thickness } \\
\tau[\mathrm{mm}]\end{array}$ & $\begin{array}{c}\text { Length } \\
L[\mathrm{~m}]\end{array}$ \\
\hline 1 & Steel & L290 & 210000.00 & 290.00 & 355.00 & 8.00 & 6614.00 \\
2 & Steel & $20 \#$ & 210000.00 & 245.00 & 219.00 & 6.00 & 4580.00 \\
3 & Steel & $20 \#$ & 210000.00 & 245.00 & 219.00 & 6.00 & 962.00 \\
4 & Steel & $20 \#$ & 210000.00 & 245.00 & 219.00 & 6.00 & 2187.00 \\
5 & Steel & $20 \#$ & 210000.00 & 245.00 & 219.00 & 6.00 & 1320.00 \\
6 & Steel & $20 \#$ & 210000.00 & 245.00 & 114.00 & 3.50 & 334.00 \\
7 & Steel & $20 \#$ & 210000.00 & 245.00 & 89.00 & 3.00 & 1242.00 \\
8 & Steel & $20 \#$ & 210000.00 & 245.00 & 89.00 & 3.00 & 848.00 \\
9 & Steel & $20 \#$ & 210000.00 & 245.00 & 250.00 & 6.00 & 2005.00 \\
10 & Steel & $20 \#$ & 210000.00 & 245.00 & 89.00 & 3.00 & 568.00 \\
11 & Steel & $20 \#$ & 210000.00 & 245.00 & 250.00 & 6.00 & 960.00 \\
12 & Steel & $20 \#$ & 210000.00 & 245.00 & 114.00 & 3.50 & 31.00 \\
13 & Steel & $20 \#$ & 210000.00 & 245.00 & 114.00 & 3.50 & 1051.00
\end{tabular}




\begin{tabular}{llllllll}
14 & Steel & $20 \#$ & 210000.00 & 245.00 & 114.00 & 3.50 & 886.00 \\
15 & Steel & $20 \#$ & 210000.00 & 245.00 & 114.00 & 3.50 & 502.00 \\
16 & Steel & $20 \#$ & 210000.00 & 245.00 & 114.00 & 3.50 & 526.00 \\
17 & Steel & $20 \#$ & 210000.00 & 245.00 & 114.00 & 3.50 & 824.00 \\
18 & Steel & $20 \#$ & 210000.00 & 245.00 & 114.00 & 3.50 & 635.00 \\
19 & Steel & $20 \#$ & 210000.00 & 245.00 & 219.00 & 6.00 & 4280.00 \\
20 & Steel & $20 \#$ & 210000.00 & 245.00 & 114.00 & 3.50 & 4538.00 \\
21 & Steel & $20 \#$ & 210000.00 & 245.00 & 114.00 & 3.50 & 1736.00 \\
22 & Steel & $20 \#$ & 210000.00 & 245.00 & 114.00 & 3.50 & 1574.00 \\
23 & Steel & $20 \#$ & 210000.00 & 245.00 & 114.00 & 3.50 & 570.00 \\
24 & Steel & $20 \#$ & 210000.00 & 245.00 & 114.00 & 3.50 & 950.00 \\
25 & Steel & $20 \#$ & 210000.00 & 245.00 & 114.00 & 3.50 & 556.00 \\
26 & Steel & $20 \#$ & 210000.00 & 245.00 & 114.00 & 3.50 & 789.00 \\
27 & Steel & $20 \#$ & 210000.00 & 245.00 & 114.00 & 3.50 & 1190.00 \\
28 & Steel & $20 \#$ & 210000.00 & 245.00 & 219.00 & 6.00 & 2125.00 \\
29 & Steel & $20 \#$ & 210000.00 & 245.00 & 114.00 & 3.50 & 2580.00 \\
30 & Steel & $20 \#$ & 210000.00 & 245.00 & 114.00 & 3.50 & 1974.00 \\
31 & Steel & $20 \#$ & 210000.00 & 245.00 & 114.00 & 3.50 & 1843.00 \\
32 & Steel & $20 \#$ & 210000.00 & 245.00 & 114.00 & 3.50 & 1385.00 \\
\hline
\end{tabular}

Table 3 Parameters used in this study

\begin{tabular}{cccccc}
\hline Site type & $c_{s}[\mathrm{~m} / \mathrm{s}]$ & $T_{g}[\mathrm{~s}]$ & $k_{1}\left[\mathrm{~N} / \mathrm{mm}^{3}\right]$ & $k$ & $\delta$ \\
\hline II & 200 & 0.45 & 0.06 & 1.4 & 0.6 \\
\hline
\end{tabular}

Table 4 PGV with respect to seismic intensity

\begin{tabular}{cccccccc}
\hline Seismic intensity & VI & \multicolumn{2}{c}{ VII } & \multicolumn{2}{c}{ VIII } & IX & X \\
\hline PGA [g] & 0.05 & 0.10 & 0.15 & 0.20 & 0.30 & 0.40 & 0.80 \\
PGV [mm/s] & 60 & 130 & 195 & 250 & 375 & 500 & 1000 \\
\hline
\end{tabular}

The maximum stress and corresponding earthquake damage index of each pipeline are calculated using Eq. 9 and Eq. 10, and the values of earthquake damage index are shown in Table 5. And the earthquake damage index values of gas pipeline network are calculated using Eq. 11, as denoted in Table 6.

Table 5 Earthquake damage index of each gas pipeline $(D I)$

\begin{tabular}{cccccccc}
\hline \multirow{2}{*}{ No. } & \multicolumn{7}{c}{ Seismic intensity } \\
\cline { 2 - 7 } & $\mathrm{VI}(0.05 \mathrm{~g})$ & $\mathrm{VII}(0.10 \mathrm{~g})$ & $\mathrm{VII}(0.15 \mathrm{~g})$ & $\mathrm{VIII}(0.20 \mathrm{~g})$ & $\mathrm{VIII}(0.30 \mathrm{~g})$ & $\mathrm{IX}(0.40 \mathrm{~g})$ & $\mathrm{X}(0.80 \mathrm{~g})$ \\
\hline 1 & 4.51 & 2.08 & 1.39 & 1.08 & 0.72 & 0.54 & 0.27 \\
2 & 3.69 & 1.71 & 1.14 & 0.89 & 0.59 & 0.44 & 0.22 \\
3 & 3.69 & 1.71 & 1.14 & 0.89 & 0.59 & 0.44 & 0.22 \\
4 & 3.69 & 1.71 & 1.14 & 0.89 & 0.59 & 0.44 & 0.22 \\
5 & 3.69 & 1.71 & 1.14 & 0.89 & 0.59 & 0.44 & 0.22 \\
6 & 3.55 & 1.64 & 1.09 & 0.85 & 0.57 & 0.43 & 0.21 \\
7 & 3.53 & 1.63 & 1.09 & 0.85 & 0.56 & 0.42 & 0.21 \\
8 & 3.53 & 1.63 & 1.09 & 0.85 & 0.56 & 0.42 & 0.21 \\
9 & 3.70 & 1.71 & 1.14 & 0.89 & 0.59 & 0.44 & 0.22 \\
10 & 3.53 & 1.63 & 1.09 & 0.85 & 0.56 & 0.42 & 0.21 \\
11 & 3.70 & 1.71 & 1.14 & 0.89 & 0.59 & 0.44 & 0.22 \\
12 & 3.55 & 1.64 & 1.09 & 0.85 & 0.57 & 0.43 & 0.21 \\
13 & 3.55 & 1.64 & 1.09 & 0.85 & 0.57 & 0.43 & 0.21
\end{tabular}




\begin{tabular}{llllllll}
14 & 3.55 & 1.64 & 1.09 & 0.85 & 0.57 & 0.43 & 0.21 \\
15 & 3.55 & 1.64 & 1.09 & 0.85 & 0.57 & 0.43 & 0.21 \\
16 & 3.55 & 1.64 & 1.09 & 0.85 & 0.57 & 0.43 & 0.21 \\
17 & 3.55 & 1.64 & 1.09 & 0.85 & 0.57 & 0.43 & 0.21 \\
18 & 3.55 & 1.64 & 1.09 & 0.85 & 0.57 & 0.43 & 0.21 \\
19 & 3.69 & 1.71 & 1.14 & 0.89 & 0.59 & 0.44 & 0.22 \\
20 & 3.55 & 1.64 & 1.09 & 0.85 & 0.57 & 0.43 & 0.21 \\
21 & 3.55 & 1.64 & 1.09 & 0.85 & 0.57 & 0.43 & 0.21 \\
22 & 3.55 & 1.64 & 1.09 & 0.85 & 0.57 & 0.43 & 0.21 \\
23 & 3.55 & 1.64 & 1.09 & 0.85 & 0.57 & 0.43 & 0.21 \\
24 & 3.55 & 1.64 & 1.09 & 0.85 & 0.57 & 0.43 & 0.21 \\
25 & 3.55 & 1.64 & 1.09 & 0.85 & 0.57 & 0.43 & 0.21 \\
26 & 3.55 & 1.64 & 1.09 & 0.85 & 0.57 & 0.43 & 0.21 \\
27 & 3.55 & 1.64 & 1.09 & 0.85 & 0.57 & 0.43 & 0.21 \\
28 & 3.69 & 1.71 & 1.14 & 0.89 & 0.59 & 0.44 & 0.22 \\
29 & 3.55 & 1.64 & 1.09 & 0.85 & 0.57 & 0.43 & 0.21 \\
30 & 3.55 & 1.64 & 1.09 & 0.85 & 0.57 & 0.43 & 0.21 \\
31 & 3.55 & 1.64 & 1.09 & 0.85 & 0.57 & 0.43 & 0.21 \\
32 & 3.55 & 1.64 & 1.09 & 0.85 & 0.57 & 0.43 & 0.21 \\
\hline
\end{tabular}

Table 6 Earthquake damage index of gas pipeline network $(D N)$

\begin{tabular}{cccccccc}
\hline $\mathrm{SI}$ & $\mathrm{VI}(0.05 \mathrm{~g})$ & $\mathrm{VII}(0.10 \mathrm{~g})$ & $\mathrm{VII}(0.15 \mathrm{~g})$ & $\mathrm{VIII}(0.20 \mathrm{~g})$ & $\mathrm{VIII}(0.30 \mathrm{~g})$ & $\mathrm{IX}(0.40 \mathrm{~g})$ & $\mathrm{X}(0.80 \mathrm{~g})$ \\
\hline$D N$ & 3.72 & 1.72 & 1.15 & 0.89 & 0.60 & 0.45 & 0.22 \\
\hline
\end{tabular}

Note: SI-seismic intensity; DN-earthquake damage index.

\section{Results and Discussion}

According to Table 1, Table 5 and Table 6, the seismic damage levels of each gas pipeline and pipeline network are presented under different seismic intensities, as denoted in Table 7 and Table 8, respectively.

Table 7 Estimated results of each gas pipeline

\begin{tabular}{cccccccc}
\hline \multirow{2}{*}{ No. } & \multicolumn{7}{c}{ Seismic intensity } \\
\cline { 2 - 7 } & VI $(0.05 \mathrm{~g})$ & VII $(0.10 \mathrm{~g})$ & VII $(0.15 \mathrm{~g})$ & VIII $(0.20 \mathrm{~g})$ & VIII $(0.30 \mathrm{~g})$ & $\mathrm{IX}(0.40 \mathrm{~g})$ & $\mathrm{X}(0.80 \mathrm{~g})$ \\
\hline 1 & Intact & Intact & Intact & Intact & Moderate & Severe & Destroy \\
2 & Intact & Intact & Intact & Moderate & Severe & Destroy & Destroy \\
3 & Intact & Intact & Intact & Moderate & Severe & Destroy & Destroy \\
4 & Intact & Intact & Intact & Moderate & Severe & Destroy & Destroy \\
5 & Intact & Intact & Intact & Moderate & Severe & Destroy & Destroy \\
6 & Intact & Intact & Intact & Moderate & Severe & Destroy & Destroy \\
7 & Intact & Intact & Intact & Moderate & Severe & Destroy & Destroy \\
8 & Intact & Intact & Intact & Moderate & Severe & Destroy & Destroy \\
9 & Intact & Intact & Intact & Moderate & Severe & Destroy & Destroy \\
10 & Intact & Intact & Intact & Moderate & Severe & Destroy & Destroy \\
11 & Intact & Intact & Intact & Moderate & Severe & Destroy & Destroy \\
12 & Intact & Intact & Intact & Moderate & Severe & Destroy & Destroy \\
13 & Intact & Intact & Intact & Moderate & Severe & Destroy & Destroy \\
14 & Intact & Intact & Intact & Moderate & Severe & Destroy & Destroy \\
15 & Intact & Intact & Intact & Moderate & Severe & Destroy & Destroy \\
16 & Intact & Intact & Intact & Moderate & Severe & Destroy & Destroy \\
17 & Intact & Intact & Intact & Moderate & Severe & Destroy & Destroy
\end{tabular}




\begin{tabular}{|c|c|c|c|c|c|c|c|}
\hline 18 & Intact & Intact & Intact & Moderate & Severe & Destroy & Destroy \\
\hline 19 & Intact & Intact & Intact & Moderate & Severe & Destroy & Destroy \\
\hline 20 & Intact & Intact & Intact & Moderate & Severe & Destroy & Destroy \\
\hline 21 & Intact & Intact & Intact & Moderate & Severe & Destroy & Destroy \\
\hline 22 & Intact & Intact & Intact & Moderate & Severe & Destroy & Destroy \\
\hline 23 & Intact & Intact & Intact & Moderate & Severe & Destroy & Destroy \\
\hline 24 & Intact & Intact & Intact & Moderate & Severe & Destroy & Destroy \\
\hline 25 & Intact & Intact & Intact & Moderate & Severe & Destroy & Destroy \\
\hline 26 & Intact & Intact & Intact & Moderate & Severe & Destroy & Destroy \\
\hline 27 & Intact & Intact & Intact & Moderate & Severe & Destroy & Destroy \\
\hline 28 & Intact & Intact & Intact & Moderate & Severe & Destroy & Destroy \\
\hline 29 & Intact & Intact & Intact & Moderate & Severe & Destroy & Destroy \\
\hline 30 & Intact & Intact & Intact & Moderate & Severe & Destroy & Destroy \\
\hline 31 & Intact & Intact & Intact & Moderate & Severe & Destroy & Destroy \\
\hline 32 & Intact & Intact & Intact & Moderate & Severe & Destroy & Destroy \\
\hline
\end{tabular}

Table 8 Estimated results of gas pipeline network

\begin{tabular}{cccccccc}
\hline SI & $\mathrm{VI}(0.05 \mathrm{~g})$ & $\mathrm{VII}(0.10 \mathrm{~g})$ & $\mathrm{VII}(0.15 \mathrm{~g})$ & $\mathrm{VIII}(0.20 \mathrm{~g})$ & $\mathrm{VIII}(0.30 \mathrm{~g})$ & $\mathrm{IX}(0.40 \mathrm{~g})$ & $\mathrm{X}(0.80 \mathrm{~g})$ \\
\hline $\mathrm{EDL}$ & Intact & Intact & Intact & Moderate & Severe & Destroy & Destroy \\
\hline
\end{tabular}

Note: EDL-earthquake damage level.

Individual Pipeline. It can be seen from Table 7, the seismic damage levels of all of the individual pipelines are intact with respect to seismic intensity in grade VI and VII, ones of virtually all of the pipelines other than pipeline 1 are moderate damage, severe damage and destroy under seismic intensity in grade VIII (PGA=0.20g), VIII (PGA=0.30g) and IX respectively, and ones of all of the pipelines are destroy to seismic intensity in grade $\mathrm{X}$. The estimated results show that pipeline 1 has better seismic performance and the seismic design of the pipelines meets the demands of the city with fortification intensity in grade VII. The results can be useful for gas engineers.

Pipeline Network. From Table 8, it can be seen that the seismic damage levels of the pipeline network are intact, intact, intact, moderate damage, severe damage, destroy and destroy in respect of seismic intensity in grade VI, VII (PGA=0.10g), VII (PGA=0.15g), VIII (PGA=0.20g), VIII $(\mathrm{PGA}=0.30 \mathrm{~g})$, IX and $\mathrm{X}$. The results show a very good agreement with the conclusions of the earthquake site investigation of pipeline network in higher seismic intensity (VIII, IX and X). The results will provide the reference information for the government decision makers and the public.

\section{Conclusions}

To improve the earthquake damage estimation method of gas continuous buried pipelines, the semi-empirical and semi-theoretical method subjected to seismic wave propagation is used, and the weighted statistical average method is introduced to calculate the earthquake damage index of pipeline network from the estimated results of all of the individual pipelines. And the relationship between earthquake damage index and earthquake damage level is presented in this study. The results of numerical example show that the improved method for earthquake damage estimation of gas buried pipelines and pipeline network is effective and practical.

\section{Acknowledgements}

This work was financially supported by the National Science and Technology Support Plan of China (2015BAK17B05) and the Special Research in Chinese Seismological Industry (201508023), and supported by Program for Innovative Research Team in China Earthquake Administration. 


\section{References}

[1] E.D. Guo, et al. in: Proceedings of Conference on Earthquake Engineering and Earthquake Disaster Reduction, Seismological Press, China, (2009), p. 576-582. (in Chinese)

[2] X.J. Wang, et al.: World Earthq. Engin., Vol. 28(4) (2012), p. 44-50. (in Chinese)

[3] Dames and Moore, Inc.: Journal of Disaster Recovery, Vol. 3(2) (1999), p. 8.

[4] EQE International in: The January 17, 1995 Kobe Earthquake: An EQE summary report, (1995).

[5] W.W. Chen, et al. in: Symposium of 6th Int'l Conference on Seismic Zonation, USA, (2000).

[6] N.H. Gao, et al.: Journal of Catastrophology, Vol. 25(3) (2010), p. 71-76. (in Chinese)

[7] E.D. Guo, et al.: World Earthquake Engineering, Vol. 28(2) (2012), p. 8-13. (in Chinese)

[8] Z.C. Pei, et al.: Northwestern Seismological Journal, Vol. 27(2) (2005), p. 186-189. (in Chinese)

[9] M.X. Deng, et al.: Earthq. Engin. and Engin. Vibr., Vol. 21(1) (2001), p. 94-98. (in Chinese)

[10] N.M. Newmark in: Proceedings of the Int'l Symposium on Wave Propagation and Dynamic Properties of Earth Materials, USA, (1967), p. 7-26.

[11] A.Sakurai and T.Takahashi in: 4WCEE, Chile, (1969), p. 81-95.

[12] R. Flores-Berrones and X. Li Liu: Geofisica Internacional, Vol. 42(2) (2003), p 237-246.

[13] N. Nashio, et al. in: 9WCEE, Japan, Vol. 7 (1988).

[14] P. Shi, et al. in: 14WCEE, China, (2008).

[15] G.P. Kouretzis, et al. in: 15WCEE, Portugal, (2012).

[16] P. Kazemi and H. Saffari: Int'l J. of Educational Advancement, Vol. 7(2) (2016), p. 342-353.

[17] J. Li: Lifeline Aseismic Engineering-Basic Theory and Applications (Science Press, China, 2005). (in Chinese) 